\title{
Educational stays abroad and the development of self-perceived grit: A longitudinal analysis in young adulthood
}

\author{
Fabian Wolff ${ }^{1}$ (D) - Fabian T. C. Schmidt ${ }^{2} \cdot$ Christoph Borzikowsky $^{3} \cdot$ Jens Möller $^{1} \cdot$ Jenny Wagner $^{4}$ \\ Published online: 16 January 2020 \\ (C) The Author(s) 2020
}

\begin{abstract}
Grit can be viewed as a facet of conscientiousness consisting of the two sub-facets perseverance of effort and consistency of interest. Although ample research illustrates the importance of grit for educational attainment, little is known about its developmental trajectories. The goal of the present study was to examine the development of self-perceptions in the two grit facets during educational stays abroad in young adulthood. We measured grit in a sample of 179 German sojourners, who went abroad for some type of educational stay, immediately before the start of their stay abroad (T1), 3 months afterwards (T2), and 15 months afterwards (T3). We compared the developmental trajectories across T1 and T2 with a control group of 112 Germans staying at home during this period. Multivariate latent change score models showed an increase in perseverance of effort between T1 and $\mathrm{T} 2$ in the group of sojourners, which did not emerge in the control group and persisted throughout $\mathrm{T} 3$. Consistency of interest did not change between $\mathrm{T} 1$ and $\mathrm{T} 2$, but sojourners showed an increase in consistency of interest between $\mathrm{T} 1$ and $\mathrm{T} 3$. This change was positively predicted by the time sojourners had spent abroad. Although we found different developmental trajectories for perseverance of effort and consistency of interest, substantial correlated change between these facets indicated similar processes to account for change in both traits. We discuss implications for research on the development of grit as well as the role of educational stays abroad.
\end{abstract}

Keywords Grit · Perseverance of effort · Consistency of interest · Conscientiousness · Educational stays abroad · International experience

\section{Introduction}

Grit describes the personality trait to pursue long-term goals persistently despite challenges and obstacles. It consists of the

First submitted 5th of July, 2019 Re-submitted with major revisions 24th of November, 2019

Electronic supplementary material The online version of this article (https://doi.org/10.1007/s12144-019-00600-7) contains supplementary material, which is available to authorized users.

Fabian Wolff

fwolff@ipl.uni-kiel.de

Fabian T. C. Schmidt

fabian.schmidt@uni-hamburg.de

Christoph Borzikowsky

borzikowsky@medinfo.uni-kiel.de

Jens Möller

jmoeller@ipl.uni-kiel.de

Jenny Wagner

jenny.wagner@uni-hamburg.de two facets perseverance of effort, the tendency to work hard even in the face of setbacks, and consistency of interest, the tendency to not change goals and interests frequently. Duckworth et al. (2007) introduced the construct to explain

\footnotetext{
Institute for Psychology of Learning and Instruction, Kiel University, Olshausenstraße 75, D-24118 Kiel, Germany

2 Faculty of Education, University of Hamburg, Von-Melle-Park 8, D-20146 Hamburg, Germany

3 Institute of Medical Informatics and Statistics, Kiel University, Brunswiker Straße 10, D-24105 Kiel, Germany

4 Institute for Psychology, University of Hamburg, Von-Melle-Park 5, D-20146 Hamburg, Germany
} 
inter-individual differences in accomplishments between individuals of equal cognitive ability. Considering the history of research investigating indicators for personal success (e.g., Cox 1926; Galton 1892; Terman and Oden 1947), they concluded that non-cognitive qualities like perseverance, zeal, and integration toward goals were important traits for achievement in addition to talent or intelligence and narrowed them down to a new concept they labeled grit. Indeed, previous research showed that grit is a relevant predictor of educational and vocational outcomes. For example, grit predicted students' academic achievements in class and at extracurricular competitions (Duckworth et al. 2007; Duckworth and Quinn 2009; Eskreis-Winkler et al. 2014; Schmidt et al. 2017; Strayhorn 2014). Furthermore, it predicted teachers' effectiveness (Duckworth et al. 2009; Robertson-Kraft and Duckworth 2014) and retention of novice teachers in their classrooms (Robertson-Kraft and Duckworth 2014), of sales employees in their workplace (Eskreis-Winkler et al. 2014), and of cadets in the military (Duckworth et al. 2007; Duckworth and Quinn 2009). Overall, grit seems to play an important role in achievement and retention, both of which are highly relevant for success in life.

However, although high grit levels seem generally desirable, until now it is unclear whether and how grit develops in young adulthood. Interventions aiming to foster grit have hardly been evaluated (e.g., Abboud 2017; Eskreis-Winkler 2015) and to the best of our knowledge only three studies have examined the development of grit longitudinally (Duckworth and Quinn 2009; Park et al. 2018; Raphiphatthana et al. 2018). Addressing this research gap, the present paper is the first to examine the development of perseverance of effort and consistency of interest within a sample of young German adults who take part in an educational stay abroad of at least threemonth duration. Using a prospective control group design with up to three measurement points, we examined both short-term (3 months) and long-term (15 months) effects of educational stays abroad on the development of selfperceptions in the two grit facets. Taking into account new empirical evidence regarding the conceptualization of grit (Schmidt et al. 2018b), we consider grit as a certain facet of conscientiousness with its own sub-facets perseverance of effort and consistency of interest.

\section{Conceptualization of Grit}

\section{Grit as a Facet of Conscientiousness}

In recent years, the significance of grit has been discussed controversially, especially because of its strong relation to the Big Five trait conscientiousness. Most prominently, in a meta-analysis on the relevance of grit, Credé et al. (2016) found a correlation of $\rho=.84$ between global grit and conscientiousness (and of $\rho=.83$ between perseverance of effort and conscientiousness as well as $\rho=.61$ between consistency of interest and conscientiousness), leading them to the conclusion that grit merely represented a new label for conscientiousness. However, this criticism overlooked the fact that conscientiousness and grit describe two personality traits located at different levels of hierarchy (Schmidt et al. 2018b). Whereas conscientiousness is conceptualized as a broad, multifaceted personality trait describing individual differences in the tendency to be self-controlled, responsible to others, hardworking, orderly, and rule-abiding (Roberts et al. 2009), grit can be viewed as the proactive aspect and thus a facet of conscientiousness (Schmidt et al. 2018b).

Moreover, by demonstrating the close empirical relatedness between grit and a number of mostly short compound measures of conscientiousness, Credé et al. (2016) disregarded the heterogeneity of conscientiousness. Being such a broad trait, the meaning of conscientiousness depends to some extent on the applied measure. Recent research has shown that the relations between conscientiousness and external criteria can vary as a function of the used conscientiousness scale (MacCann et al. 2009; Roberts et al. 2005). Also considering that specific lower-order facets of conscientiousness can provide a good or even better prediction of specific behavioral outcomes than domain general assessments (MacCann et al. 2009; Mõttus et al. 2017; Paunonen 1998; Paunonen and Ashton 2001), it seems reasonable to analyze conscientiousness on the facet level rather than as an omnibus construct. In the present study, this is partially realized, as we analyze grit as one facet of conscientiousness.

\section{Perseverance of Effort and Consistency of Interest as Facets of Grit}

Although there is no consensus about the existence of a general grit factor (e.g., Credé et al. 2016; Muenks et al. 2017; Steinmayr et al. 2018), previous research has often not differed between perseverance of effort and consistency of interest when analyzing grit (Credé et al. 2016). However, similar to differentiating between single facets of global conscientiousness, it seems advisable to analyze the two facets of grit separately. For example, Schmidt et al. (2018b) found that the facets of grit showed differential associations with a set of conscientiousness facets and higher-level factors. Whereas perseverance of effort was stronger related to the industriousness factor than consistency of interest, the latter was additionally correlated with the self-discipline facet of conscientiousness. Investigating the relations of the grit facets with external criteria, Credé et al. (2016) found that, despite a strong correlation of $\rho=.60$ between the grit facets, perseverance of effort exhibited much stronger associations with academic performance than consistency of interest. In contrast, Schmidt et al. (2018a) found, among others, that crystallized intelligence was stronger related to consistency of interest than to 
perseverance of effort. These findings indicate that both grit facets can function differently and have predictive value depending on the outcome under investigation. Accordingly, we analyze both facets separately in the present research.

\section{Personality Development during Educational Stays Abroad}

Weichbrodt (2014) defines educational stays abroad as prolonged, but time-limited sojourns in other countries than the country of origin, which at least partially have a direct or indirect educational purpose. They are usually undertaken as independent travels during adolescence or early adulthood. Typical forms are student exchanges, internships abroad, au pair stays, voluntary services, and work-and-travel turns. Educational stays abroad constitute a central event in young adults' lives (Zimmermann and Neyer 2013). Three characteristics appear to be particularly important: Firstly, such stays are commonly organized independently and over a longer period of time. Secondly, by lasting for an extended, but limited duration, they differ from both short touristic journeys and enduring emigrations. Finally, because of their educational purpose, they have to be distinguished from vocational delegations, where earnings are generally more important than purely educational aspirations (Weichbrodt 2014).

Educational stays abroad do not only promote the development of competencies like language (e.g., Hansel 2005) or intercultural competencies (e.g., Wolff and Borzikowsky 2018), but have also been linked to personality development (e.g., Andrews et al. 1993; Greischel et al. 2016; Hutteman et al. 2015; Lüdtke et al. 2011; Niehoff et al. 2017; Ying 2002; Zimmermann and Neyer 2013). With respect to the Big Five, previous research has consistently revealed positive effects of educational stays abroad on agreeableness and emotional stability (Greischel et al. 2016; Lüdtke et al. 2011; Niehoff et al. 2017; Zimmermann and Neyer 2013). Furthermore, some studies found positive effects on either extraversion (Lüdtke et al. 2011; Niehoff et al. 2017) or openness (Greischel et al. 2016; Zimmermann and Neyer 2013). Interestingly, no study has yet found an effect of educational stays abroad on change in conscientiousness, except for a study of Greischel et al. (2016), who found a temporary increase in conscientiousness after 2 months abroad, yet vanishing after 7 months abroad, in a sample of high school students.

By now, the processes leading to personality changes during educational stays abroad are still unclear. However, different explanations have been proposed. One explanation can be deduced from the neo-socioanalytic model of personality (Roberts and Nickel 2017; Roberts and Wood 2006). The model assumes that socialization factors, such as transitional experiences and situational demands, affect personality development, and that such changes in personality are commonly preceded by changes in behavior. Accordingly, environmental demands during an educational stay abroad could create a reward structure promoting self-regulated and consistent changes in behavior, which in return could cause changes in personality traits (see also Bleidorn 2012).

Zimmermann and Neyer (2013) referred to two basic principles of personality development put forward in the neosocioanalytic model of personality to explain their findings with respect to the Big Five: (1) the Maturity Principle and (2) the Corresponsive Principle. Firstly, the Maturity Principle states that with age individuals become more emotionally stable, agreeable, and conscientious, which closely aligns with empirical findings (e.g., Roberts and Mroczek 2008; Roberts et al. 2006; Robins et al. 2001). Understanding educational stays abroad as an exceptional life event, Zimmermann and Neyer explained the increases in emotional stability and agreeableness with an accelerated maturing process that was triggered by the experiences and demands abroad (Caspi et al. 2005; Roberts and Wood 2006). However, it remained unclear why such an accelerated process of maturation could not be found for sojourners' conscientiousness (Zimmermann and Neyer 2013; see also Greischel et al. 2016; Lüdtke et al. 2011). Secondly, according to the Corresponsive Principle, "the most likely effect of life experience on personality development is to deepen the characteristics that lead people to those experiences in the first place" (Roberts et al. 2003, p. 583). Although empirical evidence is only moderate so far (Roberts and Nickel 2017), corresponsive relations could be shown between extraversion and agentic goals (Bleidorn et al. 2010) or between low emotional stability and negative life events (Jeronimus et al. 2014). Zimmermann and Neyer (2013) referred to the Corresponsive Principle to explain the increase in openness during educational stays abroad: Students who decided to study abroad for one year did not only report higher initial levels in openness than their fellow students who stayed in Germany but also increased further in openness during their stay abroad. However, the Corresponsive Principle did not fit the findings of the other Big Five traits. Although the sojourners had higher initial levels in conscientiousness and extraversion, they showed no increase in these traits. Similarly, the Corresponsive Principle only fits to development trajectories found for particular Big Five traits (especially agreeableness) in more recent studies examining personality development during educational stays abroad (Greischel et al. 2016; Niehoff et al. 2017).

\section{Development of Grit during Educational Stays Abroad}

So far, no empirical study has examined the development of grit during educational stays abroad. Given the close relationship between grit and conscientiousness, one might be inclined to infer that educational stays abroad do not affect change in grit. However, it is important to consider that 
previous research finding no effect of educational stays abroad on change in conscientiousness (Greischel et al. 2016; Lüdtke et al. 2011; Niehoff et al. 2017; Zimmermann and Neyer 2013) considered conscientiousness only as a broad, multifaceted personality trait. Thus, it would still be possible to find educational stays abroad affecting conscientiousness on the facet level. Especially, a positive effect of educational stays abroad on change of grit seems plausible.

Making use of propositions by the neo-socioanalytic model of personality, possible increases in grit in the context of educational stays abroad would align with both the Maturity Principle and the Corresponsive Principle. Regarding maturation, Credé et al. (2016) found a positive correlation of $\rho=.12$ between age and grit in their meta-analysis. Notwithstanding that the few longitudinal studies examining the development of grit found no substantial increase in mean grit scores in samples of high school students during periods of 1 year (Duckworth and Quinn 2009) and 6.5 months (Park et al. 2018), as well as in a sample of university students during a period of 4.5 months (Raphiphatthana et al. 2018), this positive correlation suggests that grit might slightly increase with age. If educational stays abroad further accelerate personality development, sojourners should illustrate a substantially stronger increase in grit during their educational stays abroad as compared to a control group of the same age. Regarding the Corresponsive Principle, it would be plausible that individuals going abroad score particularly high in grit, because the preparation of an educational stay abroad requires both perseverance of effort and consistency of interest, and that they further increase in grit during their educational stays abroad. However, bearing in mind that educational stays abroad can also bring opportunity costs with them, such as a delayed start of career due to a prolonged period of education, it is not clear whether individuals who conduct an educational stay abroad score higher in grit than individuals who do not.

While this general theoretical argumentation for an increase in grit during educational stays abroad would also apply to global conscientiousness, a more differentiated argument for an increase in grit during educational stays abroad can be found based on the specific conceptualization of the construct and the characteristics of educational stays abroad. Educational stays abroad are usually accompanied by a number of difficulties and challenges (e.g., Bochner et al. 1977; Ward and Kennedy 1993; Ward et al. 1998; Wilson et al. 2013). Sojourners are physically separated from their familiar social and cultural environment and have to find their way in a novel setting. They have to cope with intercultural differences, with communication problems, and especially individual travelers are suddenly on their own a good part of their time. Moreover, sojourners often pursue an educational goal that can pose an additional developmental challenge during the stay. If sojourners want their time abroad to be a valuable and successful experience, they have to master all of these challenges. They must not to be discouraged by obstacles and setbacks, but have to pursue their long-term project abroad and their individual goals diligently and persistently. In other words: They need grit or to develop grit.

Bringing together this argument and the neo-socioanalytic model of personality, one could hypothesize that the difficulties and challenges of educational stays abroad lead to behavioral changes, which further facilitate a general increase in grit. However, differential research of the last decade would imply that the two facets of grit possibly illustrate different developmental trajectories across educational stays abroad, because they are fueled by distinct characteristics and challenges of the experience: Research on intercultural adaptation has demonstrated that sojourners perceive adjustment difficulties most heavily during their first months abroad (Ward et al. 1998; Wilson et al. 2013). Therefore, it seems likely that sojourners have to work hard to overcome obstacles and setbacks especially during this period of familiarization with the new environment so that increases in perseverance of effort should be most pronounced in the first months abroad. In contrast, consistency of interest refers to the tendency to maintain goals and interests over periods of months to years (Duckworth et al. 2007). Accordingly, an increase in this facet might only result from the experience to have successfully mastered the project "staying abroad" over a longer period of time.

Independently of these assumed differences in the developmental trajectories of the two grit facets, both facets might illustrate stronger increases the longer a sojourner stays abroad because of the ongoing need to overcome obstacles and the potential challenge to maintain effort and interest in the project abroad. Furthermore, one might suspect that change in one facet is positively correlated to change in the other. Perseverance of effort and consistency of interest are part of the same construct (Steinmayr et al. 2018) and similar processes might account for change in these facets during educational stays abroad. For example, the more setbacks sojourners have to deal with, the greater they should perceive the effort to maintain their interest in their project abroad for a long time. However, correlated change is difficult to predict and has not been investigated with regard to the grit facets as of yet (Allemand and Martin 2016). We thus conduct exploratory analyses on correlated change between the two grit facets.

\section{The Present Study}

The present study tracked a sample of young adult sojourners from Germany who participated in an educational stay abroad of a duration of at least 3 months to examine general developmental trajectories in self-perceptions in the two grit facets during the stay abroad. We measured grit during the last 3 weeks before the start of the stay abroad (T1) as well as 
3 months (T2) and 15 months (T3) after going abroad. Moreover, we examined the development of grit between T1 and $\mathrm{T} 2$ in a control group of individuals who stayed at home during this period to separate general developmental trends from those associated with the sojourners' experiences abroad. ${ }^{1}$ Building on the empirical findings and theoretical deliberations presented above, we formulated three hypotheses. Firstly, sojourners will already show an increase in perseverance of effort during the first 3 months of their stay abroad (i.e., between T1 and T2), which will be substantially different from the change trajectory in the control group (Hypothesis 1). Secondly, sojourners will show an increase in consistency of interest only after persisting in the experience of the educational stay abroad (i.e., between T1 and T3, but not between T1 and T2; Hypothesis 2). Finally, the absolute time spent abroad (between T1 and T3) will have a positive effect on the rate of change in the grit facets (Hypothesis 3). We supplement our hypotheses with three exploratory research questions: Firstly, are there selection effects between the sojourners and the control group? Secondly, do the correlations between the initial levels and changes in the grit facets support the Corresponsive Principle? Finally, is the change between the grit facets correlated?

\section{Method}

The study took place online and in the context of the project Effects of Educational Stays Abroad at Kiel University (Wolff 2017). In the following, we will only outline the aspects of the investigation which are relevant for the present study.

\section{Sample}

Description The final sample consisted of $N=291$ participants (sojourners: $N=179$; control group: $N=112$ ) with an average age of 21.3 years $(S D=2.51)$, mainly female $(84.2 \%)$. Most of them were in a phase of or before academic training: $3.1 \%$ had a non-academic high school diploma (Mittlere Reife), $78.4 \%$ had an academic high school diploma (Abitur), 16.8\% had a bachelor's degree, and $1.7 \%$ had a master's degree. Half of the participants $(50.9 \%)$ had already spent at least 1 month at a stretch abroad. Among the sojourners, the main reason to go abroad was for a student exchange (39.7\%), a work-and-travel turn $(24.0 \%)$, an au pair stay $(21.8 \%)$, a voluntary service $(8.4 \%)$, or an internship $(6.1 \%)$. The educational stays abroad took place in 43 different countries from six continents (Europe: 38.5\%; Australia: 28.0\%; North America: 20.1\%; Asia: 5.6\%; South America: 5.0\%; Africa: 2.8\%). The most

\footnotetext{
${ }^{1}$ Originally, we had also measured grit at T3 in the control group. However, as only nine participants of the control group indicated to not have spent any time abroad between T1 and T3, we did not consider these data in the analyses.
}

visited countries were the United States (16.8\%), Australia $(16.2 \%)$, and New Zealand (11.2\%), followed by Spain (5.6\%), Great Britain (5.0\%), Canada, Norway, Turkey (each $3.4 \%$ ), Latvia, France, the Netherlands, and Sweden (each $2.8 \%)$.

Group Comparison We compared the sojourners with the control group regarding key demographics and the duration of the longest stay abroad before T1 (see Table 1). A statistically significant difference between both groups could only be found for age. On average, the sojourners were almost 2 years younger than the participants of the control group $(d=0.78)$. Yet, age showed no significant correlation with the grit facets measured at any point in time (all $|r| \leq .06$, all $p \geq .30$ ). Moreover, we controlled for age in our analyses.

Selection Initially, $N=444$ Germans between 18 and 26 years took part in the study at T1 (sojourners: $N=252$; control group: $N=192$ ). However, $N=153$ participants were excluded from the final sample because of one or more of the following reasons: (1) Participants only completed the questionnaire at T1 (sojourners: $n=16$; control group: $n=25$ ). (2) Participants could not be clearly assigned to one of the two groups because of contradictory statements $(n=3)$. (3) Participants' stays abroad could not be classified as educational $(n=2)$ or should take place in Germany $(n=2)$. (4) Sojourners took part at T1 more than 3 weeks before the start of their stay abroad $(n=7)$ or after their stay abroad had already started $(n=21)$. (5) Sojourners took part at T2 more than 105 days (3.5 months) after their stay abroad had started $(n=14)$ or participants of the control group took part at T2 more than 114 days (105 days + average interval between T1 and the start of the sojourners' stays abroad) after T1 $(n=3)$. (6) Sojourners were already back in Germany when taking part at T2 ( $n=21$, with $n=13$ participants indicating that they had terminated their stay abroad prematurely) or participants of the control group spent some time abroad between T1 and T2 $(n=48)$. To test selection effects, we compared the final sample $(N=291)$ and the excluded participants $(N=153)$ regarding key demographic variables, the duration of the longest stay abroad before T1, and the initial levels in perseverance of effort and consistency of interest (see Table 2). We found no substantial differences. Hence, the results should not have been biased by the selection of the participants.

Recruitment Participants were recruited online via social media groups and mailing lists in two waves. In the first wave, we recruited all sojourners as well as 79 participants for the control group (of these, 37 participants were included in the final sample). Because of the small number of participants in the control group, we conducted a second wave of data collection, in which we recruited 113 further participants for the control group (of these, 75 participants were included in the final 
Table 1 Sample description divided into subgroups

\begin{tabular}{|c|c|c|c|c|}
\hline Variable & $\begin{array}{l}\text { Entire Sample } \\
(N=291)\end{array}$ & $\begin{array}{l}\text { Sojourners } \\
(N=179)\end{array}$ & $\begin{array}{l}\text { Control Group } \\
(N=112)\end{array}$ & Group Comparison \\
\hline $\mathrm{Age}^{\mathrm{a}}$ & $21.32(2.51)$ & $20.61(2.40)$ & $22.44(2.26)$ & $t(289)=6.44, p<.001$ \\
\hline \multicolumn{5}{|l|}{ Gender } \\
\hline $\begin{array}{l}\text { Male } \\
\text { Female }\end{array}$ & $\begin{array}{l}46(15.8 \%) \\
245(84.2 \%)\end{array}$ & $\begin{array}{l}23(12.8 \%) \\
156(87.2 \%)\end{array}$ & $\begin{array}{l}23(20.5 \%) \\
89(79.5 \%)\end{array}$ & $\chi^{2}(1)=3.06, p=.08$ \\
\hline \multicolumn{5}{|l|}{ Educational Attainment } \\
\hline $\begin{array}{l}\text { Non-Academic High School Diploma } \\
\text { Academic High School Diploma } \\
\text { Bachelor's Degree } \\
\text { Master's Degree }\end{array}$ & $\begin{array}{l}9(3.1 \%) \\
228(78.4 \%) \\
49(16.8 \%) \\
5(1.7 \%)\end{array}$ & $\begin{array}{l}7(3.9 \%) \\
141(78.8 \%) \\
28(15.6 \%) \\
3(1.7 \%)\end{array}$ & $\begin{array}{l}2(1.8 \%) \\
87(77.7 \%) \\
21(18.8 \%) \\
2(1.8 \%)\end{array}$ & $\chi^{2}(3)=1.42, p=.70$ \\
\hline \multicolumn{5}{|l|}{ Longest Stay Abroad Before T1 } \\
\hline $\begin{array}{l}\text { Less Than } 1 \text { Month } \\
\text { At Least } 1 \text { Month }\end{array}$ & $\begin{array}{l}139(49.1 \%) \\
144(50.9 \%)\end{array}$ & $\begin{array}{l}86(50.3 \%) \\
85(49.7 \%)\end{array}$ & $\begin{array}{l}53(47.3 \%) \\
59(52.7 \%)\end{array}$ & $\chi^{2}(1)<1, p=.63$ \\
\hline
\end{tabular}

${ }^{a}$ Values label means (and standard deviations)

sample). In gratitude for participating, participants of the first wave of data collection could win one of six vouchers of a total value of $€ 100$ (approximately \$117) after completing the questionnaire at T2 as well as 1 of 20 vouchers of a total value of $€ 200$ after completing the questionnaire at T3. Participants of the second wave of data collection could win 1 of 10 vouchers of a total value of $€ 100$ after completing the questionnaire at T2. Moreover, participants of both waves were eligible to receive individualized feedback on their results. Additional analyses showed that participants of the control group of the first versus second wave of data collection neither differed in their grit scores nor in the duration of their longest stay abroad before T1. Furthermore, they showed no crucial differences in key demographics (see Supplemental Material $1)$.

\section{Procedure}

Data collection took place between June 2015 and February 2017 (first wave), as well as between April 2019 and August 2019 (second wave), with up to three online questionnaires created with LimeSurvey 2.05 (LimeSurvey Project Team, and Schmitz 2012). The questionnaires were coded with idnumbers to ensure complete anonymity. Participants registered for the study with their email addresses before T1. After registration, they received a link to the questionnaire at T1,

Table 2 Comparison of included and excluded participants

\begin{tabular}{|c|c|c|c|c|}
\hline Variable & $\begin{array}{l}\text { All Participants } \\
(N=444)\end{array}$ & $\begin{array}{l}\text { Included } \\
(N=291)\end{array}$ & $\begin{array}{l}\text { Excluded } \\
(N=153)\end{array}$ & Group Comparison \\
\hline $\mathrm{Age}^{\mathrm{a}}$ & $21.45(2.51)$ & $21.32(2.51)$ & $21.71(2.50)$ & $t(442)=1.56, p=.12$ \\
\hline \multicolumn{5}{|l|}{ Gender } \\
\hline $\begin{array}{l}\text { Male } \\
\text { Female }\end{array}$ & $\begin{array}{l}80(18.0 \%) \\
364(82.0 \%)\end{array}$ & $\begin{array}{l}46(15.8 \%) \\
245(84.2 \%)\end{array}$ & $\begin{array}{l}34(22.2 \%) \\
119(77.8 \%)\end{array}$ & $\chi^{2}(1)=2.79, p=.10$ \\
\hline \multicolumn{5}{|l|}{ Educational Attainment } \\
\hline $\begin{array}{l}\text { Non-Academic High School Diploma } \\
\text { Academic High School Diploma } \\
\text { Bachelor's Degree } \\
\text { Master's Degree }\end{array}$ & $\begin{array}{l}13(2.9 \%) \\
349(78.6 \%) \\
73(16.4 \%) \\
9(2.0 \%)\end{array}$ & $\begin{array}{l}9(3.1 \%) \\
228(78.4 \%) \\
49(16.8 \%) \\
5(1.7 \%)\end{array}$ & $\begin{array}{l}4(2.6 \%) \\
121(79.1 \%) \\
24(15.7 \%) \\
4(2.6 \%)\end{array}$ & $\chi^{2}(3)<1, p=.91$ \\
\hline \multicolumn{5}{|l|}{ Longest Stay Abroad Before T1 } \\
\hline $\begin{array}{l}\text { Less Than } 1 \text { Month } \\
\text { At Least } 1 \text { Month }\end{array}$ & $\begin{array}{l}187(46.2 \%) \\
218(53.8 \%)\end{array}$ & $\begin{array}{l}139(49.1 \%) \\
144(50.9 \%)\end{array}$ & $\begin{array}{l}48(39.3 \%) \\
74(60.7 \%)\end{array}$ & $\chi^{2}(1)=3.28, p=.07$ \\
\hline Perseverance of Effort $\mathrm{T} 1^{\mathrm{a}}$ & $3.67(0.64)$ & $3.65(0.64)$ & $3.70(0.64)$ & $t(442)<1, p=.46$ \\
\hline Consistency of Interest $T 1^{\mathrm{a}}$ & $3.19(0.70)$ & $3.22(0.70)$ & $3.15(0.71)$ & $t(442)<1, p=.34$ \\
\hline
\end{tabular}

${ }^{\mathrm{a}}$ Values label means (and standard deviations) 
which they were asked to complete during the three weeks before their stay abroad started (sojourners) or once they intended to stay in Germany for at least three months (control group). Three months after participants had submitted the questionnaire at $\mathrm{T} 1$, they were sent a second link to the questionnaire at T2. Moreover, sojourners received a third link to the questionnaire at $\mathrm{T} 3$ one year and ten weeks after the start of their stay abroad. The interval between $\mathrm{T} 1$ and $\mathrm{T} 2$ was similar for the sojourners ( $M=98.5$ days, $S D=7.56)$ and the participants of the control group $(M=97.1$ days, $S D=4.76)$. Sojourners spent $M=89.5$ days $(S D=5.96)$ abroad between $\mathrm{T} 1$ and T2. The measurement at T3 took place $M=459.2$ days $(S D=6.33)$ after the stays abroad had started. Between $\mathrm{T} 1$ and T3 participants spent around 252 days $(M=8.3$ months, $S D=$ 3.10) abroad.

\section{Measures}

Independent Variables At T1, participants indicated whether they intended to go abroad for at least three months within the next three weeks or if they planned to stay in Germany for the next three months. At T2, they stated whether they had spent their last three months abroad or in Germany. According to their statements, they were assigned to one of two subgroups (sojourners vs. control group). At T3, sojourners were asked how many months they had spent abroad between $\mathrm{T} 1$ and $\mathrm{T} 3$.

Dependent Variables To measure the two facets of grit, we applied the 12-item grit scale (Duckworth et al. 2007) in its German version (Fleckenstein et al. 2014). This scale contains six positively phrased items to assess perseverance of effort ("I have achieved a goal that took years of work"; "I have overcome setbacks to conquer an important challenge"; "I finish whatever I begin"; "Setbacks don't discourage me"; "I am a hard worker"; "I am diligent") and six negatively phrased items to assess consistency of interest ("I often set a goal but later choose to pursue a different one"; "New ideas and new projects sometimes distract me from previous ones"; "I become interested in new pursuits every few months"; "My interests change from year to year"; "I have been obsessed with a certain idea or project for a short time but later lost interest"; "I have difficulty maintaining my focus on projects that take more than a few months to complete"). We presented these items in randomized order. At all measurement points, participants responded to each item on a 5-point Likert scale ranging from $1=$ does not apply at all to $5=$ fully applies. The negatively phrased items of the consistency of interest subscale were reverse-coded, so that for both grit facets, higher scores indicated a higher manifestation of respective facet. The internal consistencies were satisfactory for both the perseverance of effort subscale (T1: $\alpha=.77 ; \mathrm{T} 2: \alpha=.74 ; \mathrm{T} 3$ : $\alpha=.79$ ) and the consistency of interest subscale (T1: $\alpha=.77 ; \mathrm{T} 2: \alpha=.81 ; \mathrm{T} 3: \alpha=.76$ ).
Control Variables At T1, participants provided their age, gender, and educational achievement. Moreover, they indicated whether they had spent at least 1 month at a stretch abroad before $\mathrm{T} 1$ (in the first wave of data collection this question was posed at T2) and answered some questions about their whereabouts in the course of the study. Participants who reported to go abroad also indicated some information about their stays abroad, such as the date their stay abroad began, the country where they resided most of the time, and their main reason to go abroad.

\section{Analytical Strategy}

We conducted our analyses in a structural equation modeling framework using Mplus 7.4 (Muthén and Muthén 2015). For model estimation, we used the robust maximum likelihood estimator (MLR; Yuan and Bentler 2000), which provides standard errors and fit statistics that correct for non-normality. We specified perseverance of effort and consistency of interest as latent variables to control for measurement error at the indicator level. We used three parcels per construct as manifest indicators, which reflected the means of two single items. Reducing indicators through parceling has the main advantages that, firstly, parcels are usually more reliable and more likely to be normally distributed than single items and, secondly, that parceling reduces the number of estimated model parameters and thus reduces the complexity of the specified model (Little et al. 2002; Little et al. 2013). We allowed correlations between the residuals of the same parcels across time to account for residual effects that cannot be ascribed to the latent factors under study (Marsh and Hau 1996). To ensure that the construct meaning of the latent constructs was the same at all measurement points, we specified scalar invariance by constraining the factor loadings and the intercepts of the indicators to be equal over time (Geiser 2013; Little et al. 2007). Detailed analyses showed that scalar invariance held both across time and between groups (see Supplemental Material 2).

As participants were obliged to respond to each item before submitting the online questionnaires, there were no missing values on single items. However, some missing values emerged because a few sojourners did not respond to the questionnaire either at T2 $(n=8)$ or at T3 $(n=21)$. To handle missing data, we used the full information maximum likelihood (FIML) procedure implemented in Mplus. This modelbased approach to handling missing data is unbiased under the missing at random assumption (MAR) and retains statistical power as no observations are deleted. Due to these advantages, FIML is considered superior in comparison to traditional missing data treatment methods such as listwise deletion (Enders 2010).

We calculated two multivariate latent change score models to estimate change in the two grit facets over time (Geiser 
2013; McArdle 2009). In Model 1, we included the sojourners and the control group and compared changes between $\mathrm{T} 1$ and T2 (see Fig. 1a). We regressed the change scores on a dummy variable indicating participants' group membership $(0=$ control group, $1=$ sojourners) to examine the effect of the educational stays abroad on the development of the grit facets. Moreover, we regressed the initial levels on this dummy variable to test for selection effects between the two groups. We allowed correlations between the change scores and initial levels. Among these, we considered the correlations between (1) the initial levels and change scores of the same facet to examine whether change trajectories differed between participants with higher and lower initial levels, (2) the change scores to examine whether change in one facet was associated with change in the other, and (3) the initial levels to compare the associations between the grit facets with findings from previous research. We controlled the change scores and initial levels for participants' age, gender, and the duration of their longest stay abroad before T1 $(0=$ less than 1 month, $1=$ at least 1 month). In Model 2, we only included the sojourners and estimated the development of the grit facets between T1 and T2 as well as between T1 and T3 (see Fig. 1b). We regressed the change scores and the initial levels on the number of months that participants spent abroad to test for effects of the duration of the stay abroad. All further model specifications were similar to Model 1 but simply extended to one additional time point.

Model fit evaluation was based on conventional criteria. In addition to the conventional $\chi^{2}$-statistic, we considered the Comparative Fit Index (CFI) and the Root Mean Square Error of Approximation (RMSEA). CFI values greater than .90 and RMSEA values lower than .08 are typically interpreted to reflect a reasonable fit to the data (Marsh et al. 2005; West et al. 2012).

\section{Results}

The Results section is structured in two sections: Firstly, we present comparisons of changes in self-perceptions of grit across sojourners and the control group between the first two measurement points (Model 1). Secondly, we concentrate on the short- and long-term developmental effects on selfperceptions in the grit facets in the group of sojourners (Model 2). Table 3 depicts the means, standard deviations, and zero-order correlations of all manifest variables used in the two analyses.

\section{Short-Term Developmental Trajectories in the Sojourners and the Control Group}

Table 4 shows the results of the latent change score model analyzing the changes in perseverance of effort and consistency of interest between $\mathrm{T} 1$ and $\mathrm{T} 2$ for all participants of our sample (Model 1). The model fit was satisfactory; $\chi^{2}(85)=204.45, p<.001 ;$ CFI $=0.929 ;$ RMSEA $=0.069$.

Change in Grit The perseverance of effort change score was significantly positive, indicating an increase in this trait in the entire sample $(d=0.16)$. In line with Hypothesis 1 , the effect of the group variable on the perseverance of effort change score was significantly positive, indicating that the increase in perseverance of effort found for the entire sample was largely due to the substantial average increase in this trait within the group of sojourners. The consistency of interest change score was significantly negative, indicating a decrease in this trait in the entire sample $(d=0.23)$. However, in line with Hypothesis 2 , the effect of the group variable on the change score in this trait was not significant (see also Fig. 2).

Selection Effects As indicated by the nonsignificant effects of the group variable on the initial levels, sojourners and participants of the control group did not significantly differ in their initial levels in the grit facets.

Correlations between Initial Levels and Change Scores The correlations between the initial levels and change scores within facets were moderately negative. Thus, participants with lower initial levels in one facet showed a steeper increase (or a weaker decrease) than participants with higher initial levels.

Correlated Change There was strongly positive correlated change between the grit facets. Hence, participants who showed a particularly strong increase in perseverance of effort also tended to show an increase in consistency of interest, whereas participants who showed a weaker increase in perseverance of effort tended to show a decrease in consistency of interest.

Correlations between Initial Levels The initial levels in perseverance of effort and consistency of interest showed a strongly positive correlation with each other.

Control Variables Participants' age, gender, and the duration of their longest stay abroad before T1 showed no significant effect on any change score. Furthermore, the control variables showed no effect on the initial scores aside from the fact that females scored slightly higher in both grit facets than males.

\section{Short- and Long-Term Developmental Trajectories in the Sojourners}

Table 5 shows the results of the latent change score model analyzing the changes in perseverance of effort and consistency of interest between $\mathrm{T} 1$ and $\mathrm{T} 2$ as well as $\mathrm{T} 1$ and $\mathrm{T} 3$ in the group of sojourners (Model 2). The model fit was satisfactory; $\chi^{2}(171)=309.99, p<.001 ;$ CFI $=0.926 ;$ RMSEA $=0.067$. 


\section{a) Model 1}

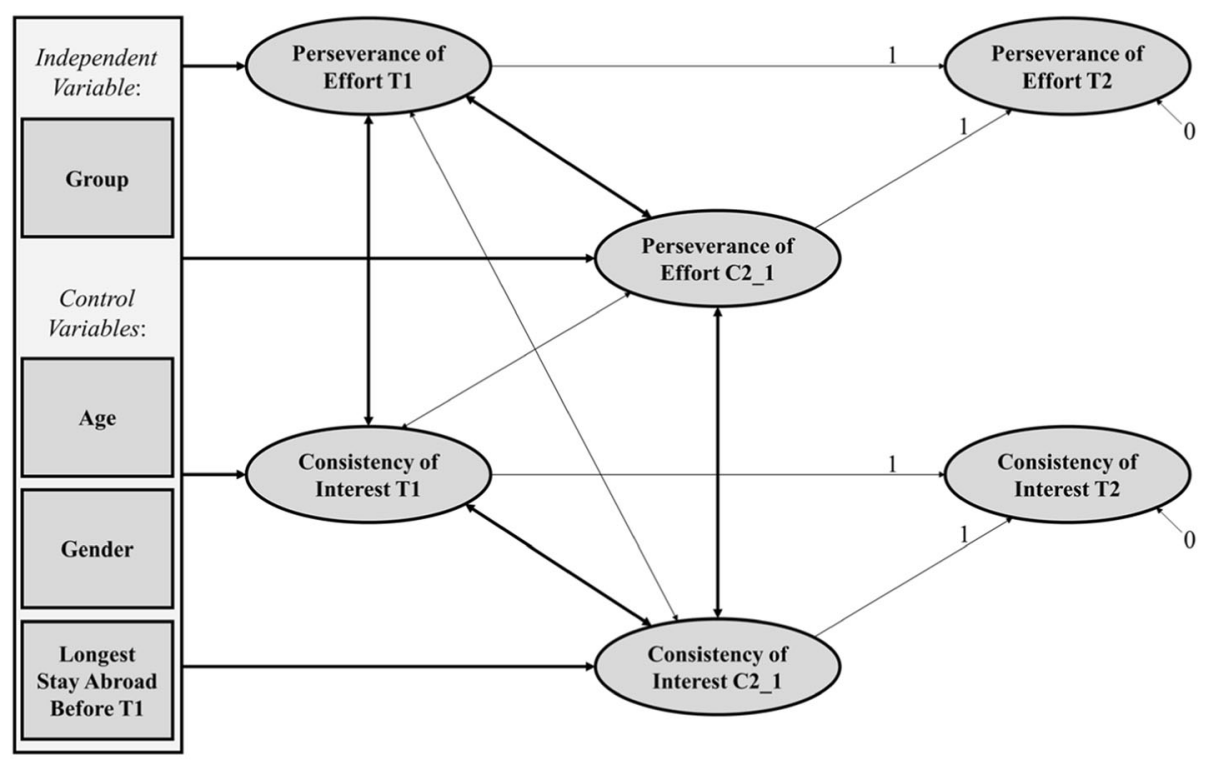

\section{b) Model 2}

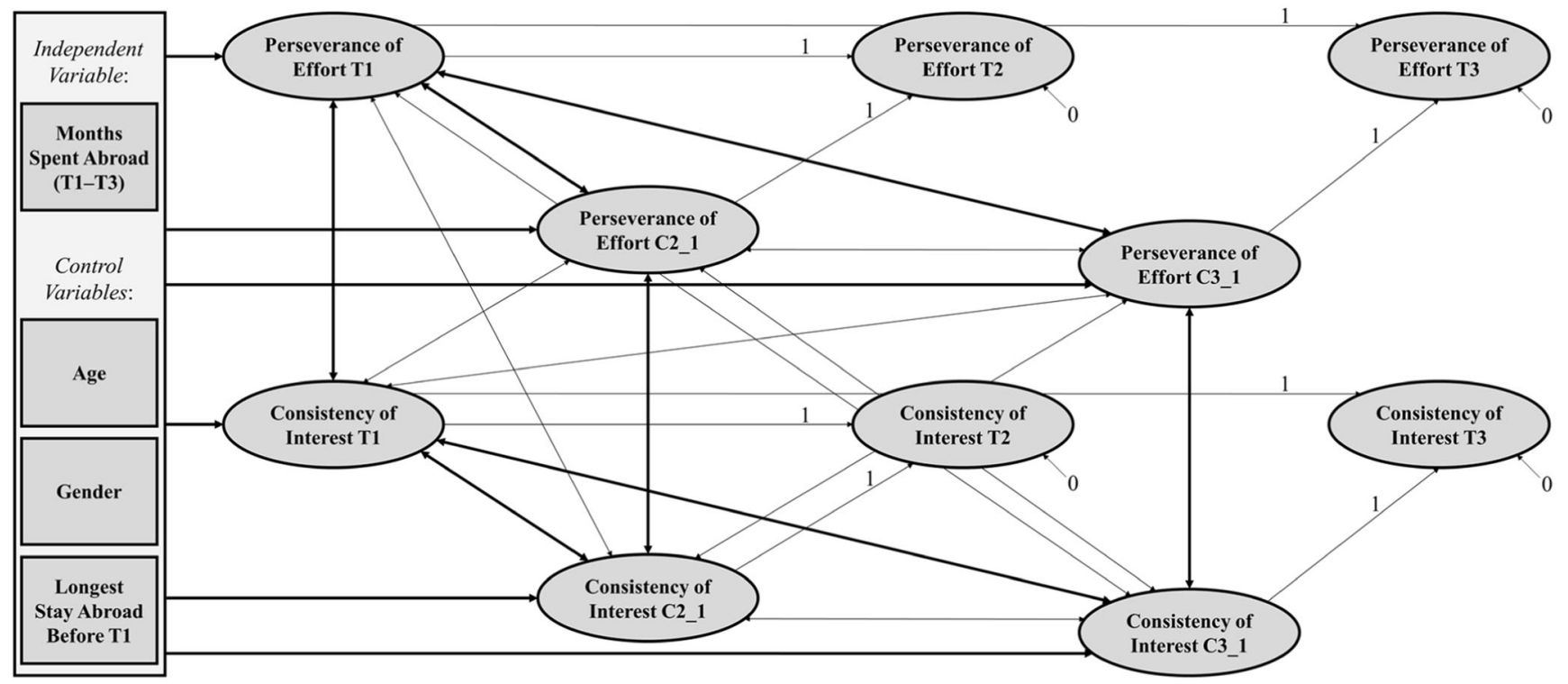

Fig. 1 Latent change score models. In Model 1, the entire sample was included $(N=291)$ and change was modeled across two measurement points. In Model 2, only the sojourners were included $(N=179)$ and change was modeled across three measurement points. Paths and correlations considered in the analyses are depicted in bold. The grit

Change in Grit In line with Hypothesis 1, both perseverance of effort change scores (T1 to $\mathrm{T} 2$ and $\mathrm{T} 1$ to $\mathrm{T} 3$, respectively) were significantly positive. Although the increase between T1 and T3 $(d=0.28)$ descriptively exceeded the increase between T1 and T2 $(d=0.21)$, the difference between the two change scores was not statistically significant $(\Delta M=0.05$, $p=.15)$. Accordingly, on average the major part of change in sojourners' perseverance of effort took place during the first 3 months of their educational stay abroad and largely manifested at this new higher level during the following year with a facets were specified as latent variables with strong measurement invariance and correlated residuals across time, but these specifications are not depicted for reasons of parsimony. Note: $\mathrm{C} 2$ - $1=$ Change from $\mathrm{T} 1$ to $\mathrm{T} 2 ; \mathrm{C} 3$ _ 1 = Change from $\mathrm{T} 1$ to $\mathrm{T} 3$

slight upward tendency. Hypothesis 2 also found support: Whereas the change in consistency of interest between T1 and $\mathrm{T} 2$ was not significantly different from zero, the change in consistency of interest between $\mathrm{T} 1$ and T3 was significantly positive $(d=0.16)$. Accordingly, sojourners showed no substantial change in consistency of interest after 3 months abroad but increased in this trait during the following months (see also Fig. 2). Hypothesis 3 assumed that the time sojourners spent abroad between $\mathrm{T} 1$ and $\mathrm{T} 3$ predicted their increase in the grit facets during this period. By and large, the results 
Table 3 Means, standard deviations, and zero-order correlations of the manifest variables in the entire sample (above the diagonal) and in the group of sojourners (below the diagonal)

\begin{tabular}{|c|c|c|c|c|c|c|c|c|c|c|c|c|}
\hline Variable & 1 & 2 & 3 & 4 & 5 & 6 & 7 & 8 & 9 & 10 & $M$ & $S D$ \\
\hline 1 Perseverance of Effort T1 & / & $.72^{* * * *}$ & / & $.51^{* * * *}$ & $.43^{* * * *}$ & / & .03 & $.12^{*}$ & .02 & 1 & 3.65 & 0.64 \\
\hline 2 Perseverance of Effort T2 & $.74^{* * * *}$ & / & / & $.48^{* * * *}$ & $.52^{* * * *}$ & / & -.03 & .11 & -.02 & / & 3.70 & 0.61 \\
\hline 3 Perseverance of Effort T3 & $.76^{* * * *}$ & $.76^{* * *}$ & / & / & / & / & / & / & / & / & / & / \\
\hline 4 Consistency of Interest $\mathrm{T} 1$ & $.52^{* * *}$ & $.54^{* * * *}$ & $.55^{* * * *}$ & / & $.76^{* * *}$ & / & .03 & $.16^{* *}$ & .09 & / & 3.22 & 0.70 \\
\hline 5 Consistency of Interest T2 & $.43^{* * * *}$ & $.57^{* * *}$ & $.55^{* * * *}$ & $.77^{* * * *}$ & / & / & -.06 & $.19^{* * *}$ & .01 & / & 3.15 & 0.72 \\
\hline 6 Consistency of Interest T3 & $.36^{* * * *}$ & $.52^{* * *}$ & $.50^{* * * *}$ & $.70^{* * * *}$ & $.66^{* * * *}$ & / & / & / & / & / & / & / \\
\hline 7 Age & -.01 & -.07 & -.06 & .06 & -.03 & .05 & l & -.11 & $.35^{* * *}$ & l & 21.32 & 2.51 \\
\hline 8 Gender $^{\mathrm{a}}$ & $.16^{*}$ & .14 & 14 & .14 & $.20^{* *}$ & .13 & -.04 & / & -.01 & / & 0.84 & 0.37 \\
\hline 9 Longest Stay Abroad Before $\mathrm{T} 1^{\mathrm{b}}$ & .10 & .03 & .05 & $.17^{*}$ & .07 & .09 & $.51^{* * *}$ & .05 & / & l & 0.51 & 0.50 \\
\hline 10 Months Spent Abroad (T1-T3) & -.04 & .01 & .03 & -.14 & -.05 & -.02 & $-.32^{* * *}$ & -.09 & $.16^{*}$ & l & I & / \\
\hline$M$ & 3.62 & 3.74 & 3.80 & 3.19 & 3.17 & 3.30 & 20.61 & 0.87 & 0.50 & 8.25 & I & / \\
\hline$S D$ & 0.68 & 0.59 & 0.66 & 0.71 & 0.72 & 0.68 & 2.40 & 0.34 & 0.50 & 3.10 & 1 & 1 \\
\hline
\end{tabular}

Entire sample: $N=291$ (T1) and $n=283$ (T2). Group of sojourners: $N=179$ (T1), $n=171$ (T2), and $n=158(\mathrm{~T} 3)$. ${ }^{\mathrm{a}} 0=$ male, $1=$ female. ${ }^{\mathrm{b}} 0=$ less than 1 month, $1=$ at least 1 month. ${ }^{*} p<.05 .{ }^{* *} p<.01 .{ }^{* * *} p<.001$

corroborated this assumption: We found a significantly positive effect of the months spent abroad on the increase in consistency of interest between T1 and T3. Yet, the effect on the increase in perseverance of effort failed to reach statistical significance $(p=.09)$.

Correlations between Initial Levels and Change Scores In line with our findings from Model 1, the correlations between the initial levels and change scores within facets were moderately to strongly negative.

Correlated Change Similar to Model 1, we found strongly positive correlated change between the grit facets between T1 and T2. However, although moderately positive, the correlation between change in the grit facets between T1 and T3 was not significant $(p=.09)$.

Correlations between Initial Levels Also in accordance with our prior findings, the initial levels in perseverance of effort and consistency of interest showed a strongly positive correlation with each other.

Control Variables Participants' time spent abroad between T1 and T3 showed no significant effect on their initial levels or change in the grit facets between T1 and T2. Participants' age, gender, and the duration of their longest stay abroad before T1 showed no significant effect on any change scores or the initial levels in the grit facets. ${ }^{2}$

\footnotetext{
${ }^{2}$ In an additional analysis, we also tested whether sojourners' initial levels or changes in the grit facets were moderated by their main reason to go abroad (student exchange vs. other kinds of stays abroad) or the destination of their stay abroad (Western countries vs. non-Western countries). We found no moderating effect (all $|\beta| \leq .14$, all $p \geq .29$; see Supplemental Material 3).
}

\section{Discussion}

The aim of the present study was to examine general developmental trajectories in self-perceptions in the two grit facets during educational stays abroad. To our knowledge, we are the first to show that educational stays abroad are related to an increase in grit, but with differential developmental trajectories for the two grit facets. Whereas sojourners showed an increase in perseverance of effort during their first 3 months abroad, consistency of interest began to increase only after 3 months abroad. In the following, we will highlight our main findings and discuss their value and implications in light of the existing limitations of our study.

\section{Development of Self-Perceived Grit during Educational Stays Abroad}

The few studies examining the longitudinal development of grit suggest that mean grit levels are usually quite stable in young adulthood and do not substantially increase within 1 year (Duckworth and Quinn 2009; Park et al. 2018; Raphiphatthana et al. 2018). In contrast, our study showed that self-perceptions in grit facets can change within such period when young adults go abroad for some type of educational stay.

In particular, the increase in perseverance of effort after only 3 months abroad is remarkable, although only small in size. The fact that we found no increase in perseverance of effort in the control group of individuals who stayed in Germany suggests that the increase in the group of sojourners might largely have been a consequence of the experience of going abroad. Importantly, before going abroad the group of sojourners was largely similar to the control group with respect to all tested variables: We found no selection effects with 
Table 4 Means, variances, correlations, and standardized regression effects with 95\% confidence intervals in Model 1

\begin{tabular}{|c|c|c|c|c|c|}
\hline Variable & $M$ & $\begin{array}{l}\text { Perseverance } \\
\text { of Effort T1 }\end{array}$ & $\begin{array}{l}\text { Consistency } \\
\text { of Interest T1 }\end{array}$ & $\begin{array}{l}\text { Perseverance } \\
\text { of Effort C2_1 }\end{array}$ & $\begin{array}{l}\text { Consistency of } \\
\text { Interest C2_1 }\end{array}$ \\
\hline Perseverance of Effort T1 & $\begin{array}{l}3.61^{* * * *} \\
{[3.51,3.70]}\end{array}$ & $\begin{array}{l}0.35^{* * * *} \\
{[0.22,0.48]}\end{array}$ & & & \\
\hline Consistency of Interest T1 & $\begin{array}{l}3.13^{*} \text {, } \\
{[3.03,3.22]}\end{array}$ & $\begin{array}{l}.65^{* * * *} \\
{[.54, .76]}\end{array}$ & $\begin{array}{l}0.37^{* * * *} \\
{[0.27,0.47]}\end{array}$ & & \\
\hline Perseverance of Effort C2_1 & $\begin{array}{l}0.06 * \\
{[0.00,0.11]}\end{array}$ & $\begin{array}{l}-.35^{* * * *} \\
{[-.53,-.18]}\end{array}$ & $\begin{array}{l}-.09 \\
{[-.28, .10]}\end{array}$ & $\begin{array}{l}0.13^{* * * *} \\
{[0.06,0.19]}\end{array}$ & \\
\hline Consistency of Interest C2_1 & $\begin{array}{l}-0.07^{*} \\
{[-0.13,-0.02]}\end{array}$ & $\begin{array}{l}-.17 \\
{[-.45, .10]}\end{array}$ & $\begin{array}{l}-.24^{*} \\
{[-.44,-.04]}\end{array}$ & {$\left[.44^{* * 3}, .76\right]$} & $\begin{array}{l}0.10^{* * * *} \\
{[0.05,0.15]}\end{array}$ \\
\hline \multicolumn{6}{|l|}{ Predictors } \\
\hline Group $^{a}$ & $0.62^{* * * *}$ & $\begin{array}{l}-.07 \\
{[-.20, .05]}\end{array}$ & $\begin{array}{l}-.09 \\
{[-.23, .05]}\end{array}$ & $\begin{array}{l}.21^{*} \\
{[.05, .38]}\end{array}$ & $\begin{array}{l}.12 \\
{[-.06, .31]}\end{array}$ \\
\hline Age & $21.32^{* * * *}$ & $\begin{array}{l}-.02 \\
{[-.17, .13]}\end{array}$ & $\begin{array}{l}-.04 \\
{[-.18, .11]}\end{array}$ & $\begin{array}{l}-.04 \\
{[-.22, .14]}\end{array}$ & $\begin{array}{l}-.13 \\
{[-.32, .07]}\end{array}$ \\
\hline Gender $^{\mathrm{b}}$ & $0.84^{* * * *}$ & $\begin{array}{l}.15^{*} \\
{[.01, .29]}\end{array}$ & $\begin{array}{l}.19^{* *} \\
{[.06, .32]}\end{array}$ & $\begin{array}{l}-.10 \\
{[-.23, .04]}\end{array}$ & $\begin{array}{l}.09 \\
{[-.11, .28]}\end{array}$ \\
\hline Longest Stay Abroad Before $\mathrm{T}^{\mathrm{c}}$ & $0.51^{* * * *}$ & $\begin{array}{l}.03 \\
{[-.11, .17]}\end{array}$ & $\begin{array}{l}.11 \\
{[-.03, .24]}\end{array}$ & $\begin{array}{l}-.06 \\
{[-.24, .11]}\end{array}$ & $\begin{array}{l}-.10 \\
{[-.30, .09]}\end{array}$ \\
\hline
\end{tabular}

Variances are depicted in the diagonal. Significant values are presented in bold. $\mathrm{C} 21=$ Change from $\mathrm{T} 1$ to $\mathrm{T} 2 .{ }^{\mathrm{a}} 0=$ control group, $1=$ sojourners. ${ }^{\mathrm{b}} 0=$ male, $1=$ female. ${ }^{\mathrm{c}} 0=$ less than 1 month, $1=$ at least 1 month. $N=291 .{ }^{*} p<.05 .{ }^{\text {*** }} p<.01 .{ }^{* * * *} p<.001$

respect to sojourners' grit facets. Regarding their demographics, both groups only slightly differed in age, which we controlled for in the analysis.

Unfortunately, no (appropriate) control group data were available for the third measurement point to test possible delayed developmental effect in this group. In particular, such data would have been useful to compare sojourners' long-term increase in consistency of interest. However, the results of prior longitudinal studies on the development of grit (Duckworth and Quinn 2009; Park et al. 2018; Raphiphatthana et al. 2018) suggest that the participants of the control group should not have shown an increase in consistency of interest up to the third measurement point. Furthermore, the positive effect of the time spent abroad on the increase in consistency of interest in the group of sojourners might be used as an indicator to draw the cautious conclusion that this increase was in large part a consequence of the completion of the stays abroad.

Although no study has examined the development of grit longitudinally across several years, the small positive correlation between grit and age (Credé et al. 2016) suggest a slight increase in grit over the life course, which allows the careful conclusion that accelerated maturation processes might have taken place during the educational stays abroad. We note that no increase in the grit facets was shown in the control group. However, we would not interpret this finding as contradicting the Maturity Principle, because it should hardly be possible to account for natural personality development within a period of 3 months (Roberts and Mroczek 2008; Roberts et al. 2006; Robins et al. 2001). Notwithstanding this, longitudinal studies on natural developmental processes in grit, encompassing periods of several years, are necessary to corroborate the interpretation that the increase in the grit facets during the educational stays abroad can be understood as a process of accelerated maturation.

In addition to the Maturity Principle we referred to the Corresponsive Principle to illustrate our assumption of an increase in grit during educational stays abroad. Contrary to the Corresponsive Principle, sojourners did not differ from participants of the control group in their initial levels in the grit facets. Furthermore, we found steeper increases in the grit facets for sojourners with lower than with higher initial levels, which also contradicts the Corresponsive Principle. These catch-up effects imply that educational stays abroad are particularly promising for individuals scoring low in grit. Possibly, the development of grit is essential for sojourners with relatively low initial grit scores to master the challenges abroad, while sojourners with high initial grit scores succeed coping with these challenges without the need increase in grit. Although catch-up effects in personality development could also result from ceiling effects, it is important to note that such effects are not taken for granted. For example, in their analysis on the development of the Big Five, Lüdtke et al. (2011) found a negative relation between initial levels and change in extraversion, openness, and conscientiousness, but a positive relation between initial level and change in emotional stability (see also Niehoff et al. 2017).

To the best of our knowledge, our study is the first examining correlated change between the grit facets. Interestingly, although perseverance of effort and consistency of interest showed different change trajectories on the group level, change in these variables was positively correlated. This finding implies that similar processes might have accounted for the change in the two facets of grit. For example, dealing with a high number of challenges abroad could not only have 
Fig. 2 Latent means for perseverance of effort and consistency of interest in the group of sojourners $(N=179)$ and the control group $(N=112)$ including $95 \%$ confidence intervals

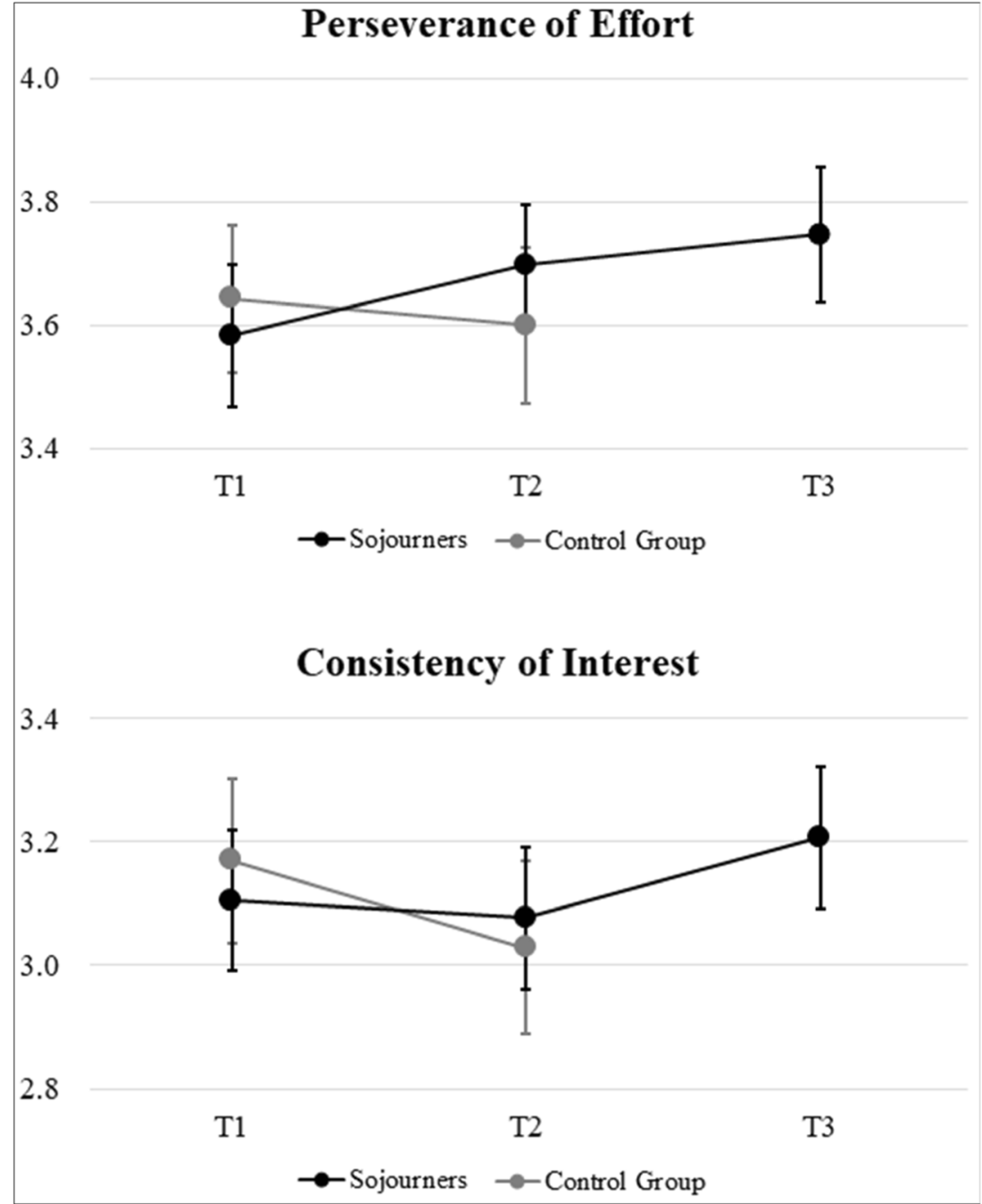

promoted sojourners' perseverance needed to master these challenges but also highlighted the effort of continually pursuing their goals abroad, thereby fostering an increase in consistency of interest. More generally, our investigation on correlated change between the grit facets contributes to the current debate concerning the subsumption of perseverance of effort and consistency of interest to grit as a higher-order construct (e.g., Credé et al. 2016). While recent research could not always replicate the assumed factorial structure of grit with its two facets (e.g., Muenks et al. 2017 vs. Steinmayr et al. 2018), our finding of strongly positive correlated change between perseverance of effort and consistency of interest provides support for this conceptualization.

\section{Strengths, Limitations and Future Directions}

In the present study, we used a prospective control group design with up to three measurement points and estimated multivariate latent change models to test an innovative research question: whether taking part in an educational stay abroad is related to an increase in grit. However, the study also had some limitations that might be addressed.

One limitation concerns the sample. Firstly, the final sample of 291 participants was relatively small. Although this sample size should be assessed with due regard to the effort of finding participants who and whose stays abroad met all the requirements of our study (e.g., restriction of educational stays abroad with a minimum duration of 3 months, data collection within a priori defined intervals, fixed age range, German citizenship, and so forth), it is possible that insufficient power hampered detecting relevant effects (e.g., the effect of the months spent abroad on the increase in perseverance of effort between T1 and T3). Secondly, our sample was self-selective. Even though the high ratio of females with an academic background might have been typical for the population of young adults undertaking educational stays abroad (see also Greischel et al. 2016; Hutteman et al. 2015; Niehoff et al. 2017; Zimmermann and Neyer 2013), it did certainly not represent the German population. Despite these shortcomings, it is worth mentioning that our sample had a number of favorable characteristics. For example, the low dropout rate 
Table 5 Means, variances, correlations, and standardized regression effects with 95\% confidence intervals in Model 2

\begin{tabular}{|c|c|c|c|c|c|c|c|}
\hline Variable & $M$ & $\begin{array}{l}\text { Perseverance } \\
\text { of Effort T1 }\end{array}$ & $\begin{array}{l}\text { Consistency } \\
\text { of Interest T1 }\end{array}$ & $\begin{array}{l}\text { Perseverance } \\
\text { of Effort C2_1 }\end{array}$ & $\begin{array}{l}\text { Perseverance of } \\
\text { Effort C3_1 }\end{array}$ & $\begin{array}{l}\text { Consistency of } \\
\text { Interest C2_1 }\end{array}$ & $\begin{array}{l}\text { Consistency of } \\
\text { Interest C3_1 }\end{array}$ \\
\hline Perseverance of Effort T1 & $\begin{array}{l}3.57^{* * *} \\
{[3.44,3.70]}\end{array}$ & $\begin{array}{l}0.32^{* * * *} \\
{[0.17,0.47]}\end{array}$ & & & & & \\
\hline Consistency of Interest $\mathrm{T} 1$ & {$[3.02,3.26]$} & {$[.52, .75]$} & $\begin{array}{l}0.34^{* * * *} \\
{[0.23,0.46]}\end{array}$ & & & & \\
\hline Perseverance of Effort C2_1 & $\begin{array}{l}0.11^{* * *} \\
{[0.04,0.18]}\end{array}$ & $\begin{array}{l}-.49^{* * *} \\
{[-.70,-.27]}\end{array}$ & $\begin{array}{l}-.13 \\
{[-.36, .11]}\end{array}$ & $\begin{array}{l}0.09^{* * *} \\
{[0.03,0.15]}\end{array}$ & & & \\
\hline Perseverance of Effort C3_1 & $\begin{array}{l}0.16^{* * * *} \\
{[0.09,0.24]}\end{array}$ & $\begin{array}{l}-.26 * \\
{[-.49,-.04]}\end{array}$ & $\begin{array}{l}.05 \\
{[-.17, .28]}\end{array}$ & $\begin{array}{l}.50^{* * * * *} \\
{[.23, .77]}\end{array}$ & $\begin{array}{l}0.12^{* * * *} \\
{[0.07,0.18]}\end{array}$ & & \\
\hline Consistency of Interest C2_1 & $\begin{array}{l}-0.02 \\
{[-0.09,0.05]}\end{array}$ & $\begin{array}{l}-.26 \\
{[-.59, .08]}\end{array}$ & {$[-.53,-.11]$} & {$\left[.52^{*}\right.$} & $\begin{array}{l}.27 \\
{[-.08, .62]}\end{array}$ & $\begin{array}{l}0.11^{* *} \\
{[0.04,0.17]}\end{array}$ & \\
\hline Consistency of Interest C3_1 & $\begin{array}{l}0.10^{*} \\
{[0.02,0.17]}\end{array}$ & $\begin{array}{l}-.24 \\
{[-.48, .01]}\end{array}$ & $\begin{array}{l}-.37^{* *} \\
{[-.59,-.15]}\end{array}$ & $\begin{array}{l}.27 \\
{[-.10, .65]}\end{array}$ & $\begin{array}{l}.27 \\
{[-.04, .59]}\end{array}$ & $\begin{array}{l}.20 \\
{[-.16, .57]}\end{array}$ & $\begin{array}{l}0.11^{* * * *} \\
{[0.06,0.17]}\end{array}$ \\
\hline \multicolumn{8}{|l|}{ Predictors } \\
\hline Months Spent Abroad (T1-T3) & $8.25^{* * * *}$ & $\begin{array}{l}-.06 \\
{[-.22, .11]}\end{array}$ & $\begin{array}{l}-.09 \\
{[-.27, .08]}\end{array}$ & $\begin{array}{l}.09 \\
{[-.15, .33]}\end{array}$ & $\begin{array}{l}.17 \\
{[-.03, .37]}\end{array}$ & $\begin{array}{l}.08 \\
{[-.17, .32]}\end{array}$ & $\begin{array}{l}.21^{*} \\
{[.01, .41]}\end{array}$ \\
\hline Age & $20.61^{* * * *}$ & $\begin{array}{l}-.14 \\
{[-.32, .04]}\end{array}$ & $\begin{array}{l}-.07 \\
{[-.25, .11]}\end{array}$ & $\begin{array}{l}-.02 \\
{[-.31, .27]}\end{array}$ & $\begin{array}{l}.04 \\
{[-.20, .28]}\end{array}$ & $\begin{array}{l}-.14 \\
{[-.37, .09]}\end{array}$ & $\begin{array}{l}.12 \\
{[-.14, .37]}\end{array}$ \\
\hline Gender $^{\mathrm{a}}$ & $0.87^{* * * *}$ & $\begin{array}{l}.17 \\
{[-.03, .36]}\end{array}$ & $\begin{array}{l}.12 \\
{[-.05, .28]}\end{array}$ & $\begin{array}{l}-.10 \\
{[-.30, .10]}\end{array}$ & $\begin{array}{l}.01 \\
{[-.14, .16]}\end{array}$ & $\begin{array}{l}.14 \\
{[-.09, .37]}\end{array}$ & $\begin{array}{l}.09 \\
{[-.13, .31]}\end{array}$ \\
\hline Longest Stay Abroad Before $\mathrm{T} 1^{\mathrm{b}}$ & $0.51^{\text {***** }}$ & $\begin{array}{l}.17 \\
{[-.02, .36]}\end{array}$ & $\begin{array}{l}.12 \\
{[-.06, .30]}\end{array}$ & $\begin{array}{l}-.18 \\
{[-.47, .11]}\end{array}$ & $\begin{array}{l}-.07 \\
{[-.32, .19]}\end{array}$ & $\begin{array}{l}-.09 \\
{[-.33, .16]}\end{array}$ & $\begin{array}{l}.01 \\
{[-.27, .29]}\end{array}$ \\
\hline
\end{tabular}

Variances are depicted in the diagonal. Significant values are presented in bold. C2 $1=$ Change from T1 to T2; C $3 \_$Change from T1 to T3. ${ }^{\mathrm{a}} 0=$ male, $1=$ female. ${ }^{\mathrm{b}} 0=$ less than 1 month, $1=$ at least 1 month. $N=179 .{ }^{*} p<.05 .{ }^{* * *} p<.01 .{ }^{* * * *} p<.001$

suggests that our participants were highly committed when taking part in the study. The wide similarity between the group of sojourners and the control group allowed drawing careful conclusions from the comparison between these two groups. Moreover, the fact that the sojourners went abroad into a plethora of countries for a heterogeneous set of occasions accounts for the external validity of our findings. However, we acknowledge that especially the small sample size urges for a replication, which should at best include a larger and - if possible - more diverse sample than our study to corroborate our findings.

Another set of limitations refers to the measures of our study. Firstly, we were not able to compare the long-term development of the grit facets between the sojourners and the control group, because appropriate control group data were only available for the first two measurement points. ${ }^{3}$ However, although additional data for the control group from the third measurement point would have further enhanced the impact of our study, we could at least refer to results of prior longitudinal studies, which found no increase in grit in samples of students not going abroad for several months (Duckworth and Quinn 2009; Park et al. 2018; Raphiphatthana et al. 2018), to compare the long-term

\footnotetext{
${ }^{3}$ We note that the nine participants of the control group (of the first wave of data collection) not going abroad between $\mathrm{T} 1$ and $\mathrm{T} 3$ descriptively showed the lowest values in the grit facets at T3. However, as noted in Footnote 1, we did not consider these data in the analyses due to the very small number of participants.
}

development of the grit facets during educational stays abroad. Secondly, we examined development trajectories during educational stays abroad only for the two grit facets, although we considered grit as a facet of conscientiousness. We confined ourselves to the investigation of grit for economic reasons and as we had theoretical assumptions about why educational stays abroad should specifically relate to an increase in this facet of conscientiousness. Nevertheless, to understand the development of conscientiousness during educational stays abroad more precisely, it would have been advantageous if we had also measured other conscientiousness facets, including global conscientiousness (as in prior studies examining personality development during educational stays abroad). Thirdly, our grit measures were based on self-reports. Thus, our study only allows drawing conclusions about changes in self-perceived grit. Although our approach was in line with prior studies examining personality development during educational stays abroad (Andrews et al. 1993; Greischel et al. 2016; Hutteman et al. 2015; Lüdtke et al. 2011; Niehoff et al. 2017; Ying 2002; Zimmermann and Neyer 2013), we cannot exclude that our findings (at least in parts) resulted from demand effects, given that participants themselves might have expected to become "grittier" during their stays abroad. To get a more differentiated view on the developmental processes that have taken place in our study, it would have been insightful to supplement participants' selfreports with external assessments of their personality. 
However, as the sojourners staying abroad were usually far away from their partners, friends, or parents at home, it might have been rather difficult to obtain valid other-ratings. In another study examining the effects of educational stays abroad, Wolff and Borzikowsky (2018) found an increase in intercultural competence measured with both a self-report questionnaire and a situational judgment test in a group of sojourners. Furthermore, previous research examining personality development showed a relatively high correspondence between self-reports and other-ratings (e.g., Göller et al. 2017). In light of these findings, one might speculate that the increase in the grit facets in the present study might not solely be based on demand effects. However, this question had to be examined empirically. Taken the mentioned limitations concerning the measures of our study together, we advise future research examining personality development during educational stays abroad using multi-methodological measures that assess conscientiousness (and other Big Five traits) on the facet level, at regular intervals and as often as possible, both in a group of sojourners and in a control group.

As a final limitation of our study, we acknowledge that, while we could demonstrate an increase in both grit facets during educational stays abroad, we still do not know which mechanisms accounted for this increase. Although we had an idea regarding the processes that might have taken place abroad and induced the increase in grit, our data were not suitable to validate these assumptions. To get closer insights into the processes affecting change in grit, it would have been of particular interest to investigate, for example, how sojourners coped with challenges abroad, whether they perceived their stays abroad as a crucial life event, and whether they judged their stays abroad as a success. Future research examining the development of grit during educational stays abroad should consider these and other possible mediators (see also Bleidorn et al. 2018).

\section{Conclusion}

In the present study, we examined the longitudinal development of self-perceived grit, understood as a specific facet of conscientiousness, during the participation in an educational stay abroad in young adulthood. According to our results, the realization of an educational stay abroad is related to an increase in both grit facets - and hence in specific subfacets of conscientiousness. This finding is of particular interest given that previous research examining the effects of educational stays abroad on change in global Big Five traits found no relation between taking part in an educational stay abroad and change in conscientiousness (Greischel et al. 2016; Lüdtke et al. 2011; Niehoff et al. 2017; Zimmermann and Neyer 2013). Although positive effects of educational stays abroad might not be found with global conscientiousness scales, it thus seems that they affect conscientiousness on the facet level; as demonstrated for grit in the present research.

Whereas an increase in consistency of interest was detectable only after more than 3 months abroad, an increase in perseverance of effort was already apparent during the first 3 months abroad. Taking into account that perseverance of effort is often considered the more relevant predictor of academic performance between the two grit facets (Credé et al. 2016) this finding is of particular practical importance. In fact, it seems possible that on average educational stays abroad of only a few months could relate to an increase in perseverance of effort, which could subsequently lead to an improvement in educational and vocational outcomes. If educational stays abroad of a longer duration additionally elicit an increase in consistency of interest, the positive effect on educational and vocational outcomes might even become stronger. Also bearing in mind the positive effects of educational stays abroad for example on the development of language or intercultural competencies, teachers, politicians, and other decision makers are highly recommended to further promote opportunities for young adults to take part in educational stays abroad. However, so far, it is unclear whether an increase in grit during an educational stay abroad can actually explain an increase in achievement-related variables. Accordingly, we encourage researchers to build on our work and pursue this question in future studies with independent samples across diverse cultures.

Funding Information Open access funding provided by Projekt DEAL. This research did not receive any specific grant from funding agencies in the public, commercial, or not-for-profit sectors.

\section{Compliance with Ethical Standards}

Conflict of Interest On behalf of all authors, the corresponding author states that there is no conflict of interest.

Ethical Approval All procedures performed in studies involving human participants were in accordance with the ethical standards of the German Research Foundation and with the 1964 Helsinki declaration and its later amendments or comparable ethical standards.

Informed Consent Informed consent was obtained from all individual participants included in the study.

Open Access This article is licensed under a Creative Commons Attribution 4.0 International License, which permits use, sharing, adaptation, distribution and reproduction in any medium or format, as long as you give appropriate credit to the original author(s) and the source, provide a link to the Creative Commons licence, and indicate if changes were made. The images or other third party material in this article are included in the article's Creative Commons licence, unless indicated otherwise in a credit line to the material. If material is not included in the article's Creative Commons licence and your intended use is not permitted by statutory regulation or exceeds the permitted use, you will need to obtain permission directly from the copyright holder. To view a copy of this licence, visit http://creativecommons.org/licenses/by/4.0/. 


\section{References}

Abboud, P. (2017). Supporting a growth mindset in high school classroom teachers (doctoral dissertation). Brandman University, Irvine, CA.

Allemand, M., \& Martin, M. (2016). On correlated change in personality. European Psychologist, 21, 237-253. https://doi.org/10.1027/10169040/a000256

Andrews, G., Page, A. C., \& Neilson, M. (1993). Sending your teenagers away: Controlled stress decreases neurotic vulnerability. Archives of General Psychiatry, 50, 585-589. https://doi.org/10.1001/archpsyc. 1993.01820190087009.

Bleidorn, W. (2012). Hitting the road to adulthood: Short-term personality development during a major life transition. Personality and Social Psychology Bulletin, 38, 1594-1608. https://doi.org/10. 1177/0146167212456707.

Bleidorn, W., Kandler, C., Hülsheger, U. R., Riemann, R., Angleitner, A., \& Spinath, F. M. (2010). Nature and nurture of the interplay between personality traits and major life goals. Journal of Personality and Social Psychology, 99, 366-379. https://doi.org/10.1037/a0019982.

Bleidorn, W., Hopwood, C. J., \& Lucas, R. E. (2018). Life events and personality trait change. Journal of Personality, 86, 83-96. https:// doi.org/10.1111/jopy.12286.

Bochner, S., McLeod, B. M., \& Lin, A. (1977). Friendship patterns of overseas students: A functional model. International Journal of Psychology, 12, 277-294. https://doi.org/10.1080/00207597708247396.

Caspi, A., Roberts, B. W., \& Shiner, R. L. (2005). Personality development: Stability and change. Annual Review of Psychology, 56, 453 484. https://doi.org/10.1146/annurev.psych.55.090902.141913.

Cox, C. M. (1926). Genetic studies of genius: Vol. 2. The early mental traits of three hundred geniuses. Stanford: Stanford University Press.

Credé, M., Tynan, M. C., \& Harms, P. D. (2016). Much ado about grit: A meta-analytic synthesis of the grit literature. Journal of Personality and Social Psychology, 113, 492-511. https://doi.org/10.1037/ pspp0000102.

Duckworth, A. L., \& Quinn, P. D. (2009). Development and validation of the short grit scale (grit-S). Journal of Personality Assessment, 91, 166-174. https://doi.org/10.1080/00223890802634290.

Duckworth, A. L., Peterson, C., Matthews, M. D., \& Kelly, D. R. (2007). Grit: Perseverance and passion for long-term goals. Journal of Personality and Social Psychology, 92, 1087-1101. https://doi.org/ 10.1037/0022-3514.92.6.1087.

Duckworth, A. L., Quinn, P. D., \& Seligman, M. E. P. (2009). Positive predictors of teacher effectiveness. Journal of Positive Psychology, 4, 540-547. https://doi.org/10.1080/17439760903157232.

Enders, C. K. (2010). Applied missing data analysis. New York: Guilford Press.

Eskreis-Winkler, L. (2015). Building grit (doctoral dissertation). University of Pennsylvania, Philadelphia, PA.

Eskreis-Winkler, L., Shulman, E. P., Beal, S. A., \& Duckworth, A. L. (2014). The grit effect: Predicting retention in the military, the workplace, school and marriage. Frontiers in Psychology, 5(36), 1-12. https://doi.org/10.3389/fpsyg.2014.00036.

Fleckenstein, J., Schmidt, F. T. C., \& Möller, J. (2014). Wer hat Biss? Beharrlichkeit und beständiges Interesse von Lehramtsstudierenden. Eine deutsche Adaptation der 12-Item Grit Scale. [Who's got grit? Perseverance and consistency of interest in pre-service teachers. A German adaptation of the 12-Item Grit Scale.] Psychologie in Erziehung und Unterricht [Psychology in Education and Lesson], 61, 281-286. https://doi.org/10.2378/peu2014.art22d .

Galton, F. (1892). Hereditary genius: An inquiry into its laws and consequences. London: Macmillan.

Geiser, C. (2013). Data analysis with Mplus. New York: Guilford Press.
Göller, R., Roberts, B. W., Damian, R. I., Lüdtke, O., Jonkmann, K., \& Trautwein, U. (2017). Whose "storm and stress" is it? Parent and child reports of personality development in the transition to early adolescence. Journal of Personality, 85, 376-387. https://doi.org/ 10.1111 jopy. 12246.

Greischel, H., Noack, P., \& Neyer, F. J. (2016). Sailing uncharted waters: Adolescent personality development and social relationship experiences during a year abroad. Journal of Youth and Adolescence, 45, 2307-2320. https://doi.org/10.1007/s10964-016-0479-1.

Hansel, B. (2005). The educational results study: The AFS internal descriptive report of the complete findings. New York: AFS Intercultural Programs, Inc..

Hutteman, R., Nestler, S., Wagner, J., Egloff, B., \& Beck, M. D. (2015). Wherever I may roam: Processes of self-esteem development from adolescence to emerging adulthood in the context of international student exchange. Journal of Personality and Social Psychology, 108, 767-783. https://doi.org/10.1037/pspp0000015.

Jeronimus, B. F., Riese, H., Sanderman, R., \& Ormel, J. (2014). Mutual reinforcement between neuroticism and life experiences: A fivewave, 16-year study to test reciprocal causation. Journal of Personality and Social Psychology, 107, 751-764. https://doi.org/ 10.1037/a0037009.

LimeSurvey Project Team \& Schmitz, C. (2012). LimeSurvey: An open source survey tool [computer software]. Hamburg: LimeSurvey Project.

Little, T. D., Cunningham, W. A., Shahar, G., \& Widaman, K. F. (2002). To parcel or not to parcel: Exploring the question, weighing the merits. Structural Equation Modeling, 9, 151-173. https://doi.org/ 10.1207/S15328007SEM0902_1.

Little, T. D., Preacher, K. J., Selig, J. P., \& Card, N. A. (2007). New developments in latent variable panel analyses of longitudinal data. International Journal of Behavioral Development, 31, 357-365. https://doi.org/10.1177/0165025407077757.

Little, T. D., Rhemtulla, M., Gibson, K., \& Schoemann, A. M. (2013). Why the items versus parcels controversy needn't be one. Psychological Methods, 18, 285-300. https://doi.org/10.1037/ a0033266.

Lüdtke, O., Roberts, B. W., Trautwein, U., \& Nagy, G. (2011). A random walk down university avenue: Life paths, life events, and personality trait change at the transition to university life. Journal of Personality and Social Psychology, 101, 620-637. https://doi.org/10.1037/ a0023743.

MacCann, C., Duckworth, A. L., \& Roberts, R. D. (2009). Empirical identification of the major facets of conscientiousness. Learning and Individual Differences, 19, 451-458. https://doi.org/10.1016/j. lindif.2009.03.007.

Marsh, H. W., \& Hau, K.-T. (1996). Assessing goodness of fit: Is parsimony always desirable? Journal of Experimental Education, 64, 364-390. https://doi.org/10.1016/10.1080/00220973.1996. 10806604

Marsh, H. W., Hau, K.-T., \& Grayson, D. (2005). Goodness of fit evaluation in structural equation modeling. In A. Maydeu-Olivares \& J. McArdle (Eds.), Contemporary psychometrics. A Festschrift for Roderick P. McDonald (pp. 275-340). Mahwah: Erlbaum.

McArdle, J. J. (2009). Latent variable modeling of differences and changes with longitudinal data. Annual Reviews of Psychology, 60, 577605. https://doi.org/10.1146/annurev.psych.60.110707.163612.

Mõttus, R., Kandler, C., Bleidorn, W., Riemann, R., \& McCrae, R. R. (2017). Personality traits below facets: The consensual validity, longitudinal stability, heritability, and utility of personality nuances. Journal of Personality and Social Psychology, 112, 474-490. https://doi.org/10.1037/pspp0000100.

Muenks, K., Wigfield, A., Yang, J. S., \& O’Neal, C. R. (2017). How true is grit? Assessing its relations to high school and college students' personality characteristics, self-regulation, engagement, and 
achievement. Journal of Educational Psychology, 109, 599-620. https://doi.org/10.1037/edu0000153.

Muthén, L. K., \& Muthén, B. O. (2015). Mplus user's guide (7th ed.). Los Angeles: Muthén \& Muthén.

Niehoff, E., Petersdotter, L., \& Freund, P. A. (2017). International sojourn experience and personality development: Selection and socialization effects of studying abroad and the Big Five. Personality and Individual Differences, 112, 55-61. https://doi.org/10.1016/j.paid.2017.02.043 .

Park, D., Yu, A., Baelen, R. N., Tsukayama, E., \& Duckworth, A. L. (2018). Fostering grit: Perceived school goal-structure predicts growth in grit and grades. Contemporary Educational Psychology, 55, 120-128. https://doi.org/10.1016/j.cedpsych.2018.09.007.

Paunonen, S. V. (1998). Hierarchical organization of personality and prediction of behavior. Journal of Personality and Social Psychology, 74, 538-556. https://doi.org/10.1037/0022-3514.74.2.538.

Paunonen, S. V., \& Ashton, M. C. (2001). Big Five predictors of academic achievement. Journal of Research in Personality, 35, 78-90. https://doi.org/10.1006/jrpe.2000.2309 .

Raphiphatthana, B., Jose, P., \& Salmon, K. (2018). Does dispositional mindfulness predict the development of grit? Journal of Individual Differences, 39, 76-87. https://doi.org/10.1027/1614-0001/a000252.

Roberts, B. W., \& Mroczek, D. (2008). Personality trait change in adulthood. Current Directions in Psychological Science, 17, 31-35. https://doi.org/10.1111/j.1467-8721.2008.00543.x.

Roberts, B. W., \& Nickel, L. B. (2017). A critical evaluation of the neosocioanalytic model of personality. In J. Sprecht (Ed.), Personality development across the lifespan (pp. 157-177). London: Academic Press.

Roberts, B. W., \& Wood, D. (2006). Personality development in the context of the neo-socioanalytic model of personality. In D. K. Mroczek \& T. D. Little (Eds.), Handbook of personality development (pp. 11-39). Mahwah: Erlbaum.

Roberts, B. W., Caspi, A., \& Moffitt, T. E. (2003). Work experiences and personality development in young adulthood. Journal of Personality and Social Psychology, 84, 582-593. https://doi.org/10.1037/00223514.84.3.582.

Roberts, B. W., Chernyshenko, O. S., Stark, S., \& Goldberg, L. R. (2005). The structure of conscientiousness: An empirical investigation based on seven major personality questionnaires. Personnel Psychology, 58, 103-139. https://doi.org/10.1111/j.1744-6570. 2005.00301.x.

Roberts, B. W., Walton, K. E., \& Viechtbauer, W. (2006). Patterns of mean-level change in personality traits across the life course: A meta-analysis of longitudinal studies. Psychological Bulletin, 132, 1-25. https://doi.org/10.1037/0033-2909.132.1.1

Roberts, B. W., Jackson, J. J., Fayard, J. V., Edmonds, G., \& Meints, J. (2009). Conscientiousness. In M. Leary \& J. Hoyle (Eds.), Handbook of individual differences in social behavior (pp. 369 381). New York: Guilford Press.

Robertson-Kraft, C., \& Duckworth, A. L. (2014). True grit: Trait-level perseverance and passion for long-term goals predicts effectiveness and retention among novice teachers. Teacher College Record, 116(3). Retrieved from https://www.ncbi.nlm.nih.gov/pmc/articles/ PMC4211426/pdf/nihms515928.pdf

Robins, R. W., Fraley, R. C., Roberts, B. W., \& Trzesniewski, K. H. (2001). A longitudinal study of personality change in young adulthood. Journal of Personality, 69, 617-640. https://doi.org/10.1111/ 1467-6494.694157.

Schmidt, F. T., Fleckenstein, J., Retelsdorf, J., Eskreis-Winkler, L., \& Möller, J. (2017). Measuring grit. European Journal of Psychological Assessment, 35, 436-447. https://doi.org/10.1027/ 1015-5759/a000407.

Schmidt, F. T. C., Lechner, C. M., Danner, D. (2018a). New wine in an old bottle: Grit as an incremental facet of conscientiousness. In F. T. C. Schmidt (Ed.), Just grit: On how to conceptualize and measure a novel trait with a long history (doctoral dissertation; pp. 137-176). Kiel University, Kiel.
Schmidt, F. T. C., Nagy, G., Fleckenstein, J., Möller, J., \& Retelsdorf, J. (2018b). Same same, but different? Relations between facets of conscientiousness and grit. European Journal of Personality, 32, 705 720. https://doi.org/10.1002/per.2171.

Steinmayr, R., Weidinger, A. F., \& Wigfield, A. (2018). Does students' grit predict their school achievement above and beyond their personality, motivation, and engagement? Contemporary Educational Psychology, 53, 106-122. https://doi.org/10.1016/j.cedpsych.2018. 02.004 .

Strayhorn, T. L. (2014). What role does grit play in the academic success of black male collegians at predominantly white institutions? Journal of African American Studies, 18, 1-10. https://doi.org/10. 1007/s12111-012-9243-0.

Terman, L. M., \& Oden, M. H. (1947). The gifted child grows up: Twentyfive years' follow-up of a superior group. Oxford: Stanford University Press.

Ward, C., \& Kennedy, A. (1993). Where's the "culture" in cross-cultural transition? Comparative studies on sojourner adjustment. Journal of Cross-Cultural Psychology, 24, 221-249. https://doi.org/10.1177/ 0022022193242006.

Ward, C., Okura, Y., Kennedy, A., \& Kojima, T. (1998). The U-curve on trial: A longitudinal study of psychological and sociocultural adjustment during cross-cultural transition. International Journal of Intercultural Relations, 22, 277-291. https://doi.org/10.1016/ S0147-1767(98)00008-X.

Weichbrodt, M. (2014). Ein Leben lang mobil? Langfristige Schüleraustauschprogramme und die spätere Mobilität der Teilnehmer als Element gesellschaftlicher Transnationalisierung. [A lifetime mobile? Long-term school exchange programs and their participants' subsequent mobility as an element of societal transnationalism.] Münster: MV-Wissenschaft.

West, S. G., Taylor, A. B., \& Wu, W. (2012). Model fit and model selection in structural equation modeling. In R. H. Hoyle (Ed.), Handbook of structural equation modeling (pp. 209-231). New York: Guilford Press.

Wilson, J., Ward, C., \& Fischer, R. (2013). Beyond culture learning theory: What can personality tell us about cultural competence? Journal of Cross-Cultural Psychology, 44, 900-927. https://doi. org/10.1177/0022022113492889.

Wolff, F. (2017). Interkulturelle Kompetenz durch Auslandsaufenthalte: Längsschnittanalyse der Wirkung dreimonatiger Auslandserfahrungen [Intercultural competence through stays abroad: Longitudinal analysis of the impact of three-month international experiences]. Wiesbaden: Springer. https://doi.org/10.1007/ 978-3-658-16392-1.

Wolff, F., \& Borzikowsky, C. (2018). Intercultural competence by international experiences? An investigation of the impact of educational stays abroad on intercultural competence and its facets. Journal of Cross-Cultural Psychology, 49, 488-514. https://doi.org/10.1177/ 0022022118754721.

Ying, Y.-W. (2002). The effect of cross-cultural living on personality: Assimilation and accommodation among Taiwanese young adults in the United States. American Journal of Orthopsychiatry, 72, 362371. https://doi.org/10.1037/0002-9432.72.3.362.

Yuan, K.-H., \& Bentler, P. M. (2000). Three likelihood-based methods for mean and covariance structure analysis with nonnormal missing data. Sociological Methodology, 30, 167-202. https://doi.org/10. 1111/0081-1750.00.

Zimmermann, J., \& Neyer, F. J. (2013). Do we become a different person when hitting the road? Personality development of sojourners. Journal of Personality and Social Psychology, 105, 515-530. https://doi.org/10.1037/a0033019.

Publisher's Note Springer Nature remains neutral with regard to jurisdictional claims in published maps and institutional affiliations. 